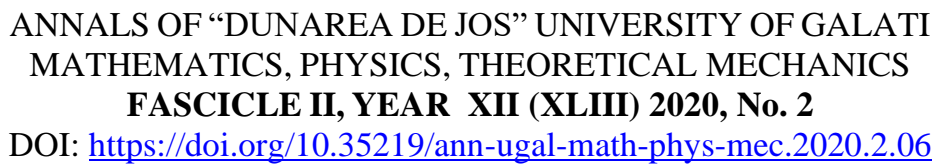

\title{
Integrating LMS and IoT in the educational system
}

\author{
Daniel Ganea $^{1}$, Marian Crăciun ${ }^{1}$, Cătălin Aramă ${ }^{1}$, Ciprian Vlad $^{1 *}$ \\ ${ }^{1}$,Dunărea de Jos” University of Galati, Romania \\ *Correspondence: Ciprian.Vlad@ugal.ro
}

\begin{abstract}
Context: Nowadays, developing computer skills is important for a student's success. Objective: Smart classrooms bring new experiences for both students and teachers not only in this current context, by increasing safety, data availability, teaching and learning optimized processes, and much more. Method: For improving the transmit and receive process (TX and RX) performances of the educational experience, we propose a system based on a Learning Management System (LMS) and the Internet of Things (IoT). Results: The results of this concept can be perceived at a theoretical level for now. LMS and IoT offer high tech solutions for sustainable and smart classrooms. The immediate result is the improvement of everyday activities and learning methods. Conclusion: The aim of this paper is to describe the efficiency of the LMS and IoT infrastructure in restructuring the traditional learning methods.
\end{abstract}

Keywords: IoT, LMS, smart classroom.

\section{INTRODUCTION}

IoT (Internet of Things) is a concept that has the potential to influence how we live and how we work. Even though this is a complex concept, once this inconvenience is overcome, the implication of our living and working experience gains new levels of optimization and sustainability. Recently, the IoT concept penetrated one of the most important domains of our society. This is the educational sector. Recent studies show both the implications, importance, and benefits of this concept. Implementing IoT in any domain can have a positive impact on cost saving, automation and control, information and communication and most importantly increasing productivity [1-4]. Obviously, this concept has also negative aspects as over dependency on technology, losing security on privacy, lesser employment prospects, and complexity $[5,6]$. To increase the functionality of IoT in the educational system, concepts like LMS (Learning Management System) should be also applied. LMS is an elearning system that provides teachers and instructors a wide range of options from which they can improve data transmission [7]. Learning Management System is an online application that can be used to manage students learning activities [8].

The aim of this paper is to draw a comprehensive picture of a proposed concept that combines IoT with LMS. By applying this concept, both faculty and students can benefit by allowing more focus on the primary tasks. This also implies less focusing on managing classroom workflow.

\section{METHOD}

Traditionally classrooms are designed to provide a face-to-face learning experience to students group work. Even though in some cases laptops and handheld devices are used, the behind curtain experience is produced in cyberspaces (Internet). Our society needs to move from the physical world to smart spaces. We propose a concept that brings to life traditionally classrooms turning them into smart classrooms. This can happen by integrating smart boards and walls, interactive projectors, new 
input and output devices, and sensors. The IoT concept is a layer based infrastructure (figure 1). The main layers are: sensory layer, communication layer, and application layer.

The sensory layer is the lowest layer of the infrastructure. The main role of this layer is to interact with the environment and users by collecting data and transferring it to the above layers $[1,9]$. In a smart classroom, this layer contains various types of sensors and devices that increase the functionality of the smart environment (Table 1).

Table 1. Sensor layer components

\begin{tabular}{|l|c|l|c|}
\hline \multicolumn{2}{|c|}{ Device } & \multicolumn{2}{c|}{ Sensor } \\
\hline projector & Functionality & \multicolumn{1}{c|}{ Type } & Functionality \\
\hline projection screen & \multirow{3}{*}{ data transfer } & surveillance camera & security \\
\cline { 3 - 4 } printer & & depth sensor & crowd management \\
\cline { 3 - 4 } & & thermal imaging camera & health management \\
\hline electric curtains & environment management & temperature sensor & \multirow{2}{*}{ environment management } \\
\hline notebook & \multirow{2}{*}{ data reception } & light sensor & \multirow{2}{*}{ disaster management } \\
\cline { 3 - 4 } & & accelerometer sensor & \\
\hline health gadget & health management & smoke and $\mathrm{CO}_{2}$ sensor & \\
\hline
\end{tabular}

The second layer of the IoT infrastructure is the communication layer. This layer can contain as a main component a SBC (Single-Board Computer) or a microcontroller (for example Arduino). In this case, a Raspberry Pi 4 Model B 4GB RAM was used (figure 2). This tiny desktop computer with dual-display can be a network AI core, a robot brain, factory controller, a smart home hub, and much more (figure 2) [10-12]. The role of a SBC is to support the IoT ecosystem. This component route the data to all IoT ecosystem layers [13, 14]. In figure 2 is presented the early stage of the experimental system. This contains a Raspberry Pi 3 connected to a video projector, a temperature sensor, keyboard, mouse, and to the Internet.

At the third layer lies the application layer. This area of the ecosystem provides service to users. In this case, this layer provides data transfer, environment management, health management, security, crowd management, disaster management, and much more. All these functionalities improve the educational process.

Figure 1 contains a supplementary layer, a layer that does not belong directly to the ecosystem, but which suggests the implications that the system may have on users. Direct beneficiaries of this system through GUI (Graphical User Interface) are students, parents, faculty, administration, and system developers.

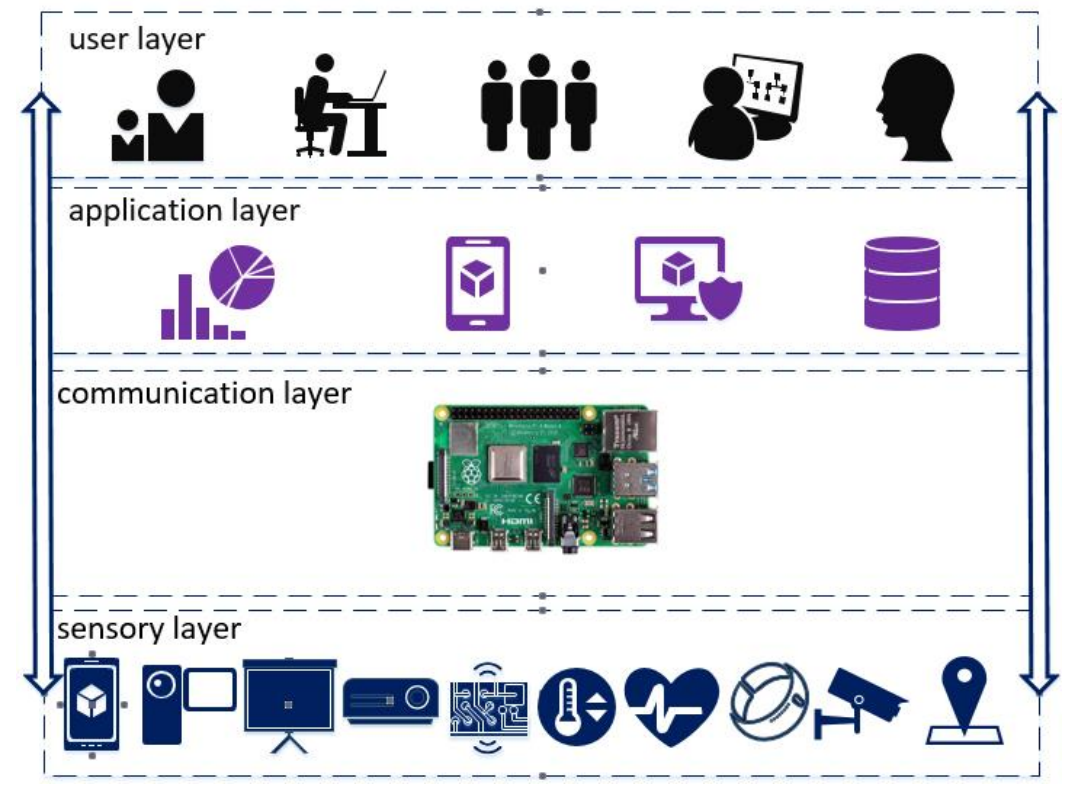

Fig. 1. The IoT layers 


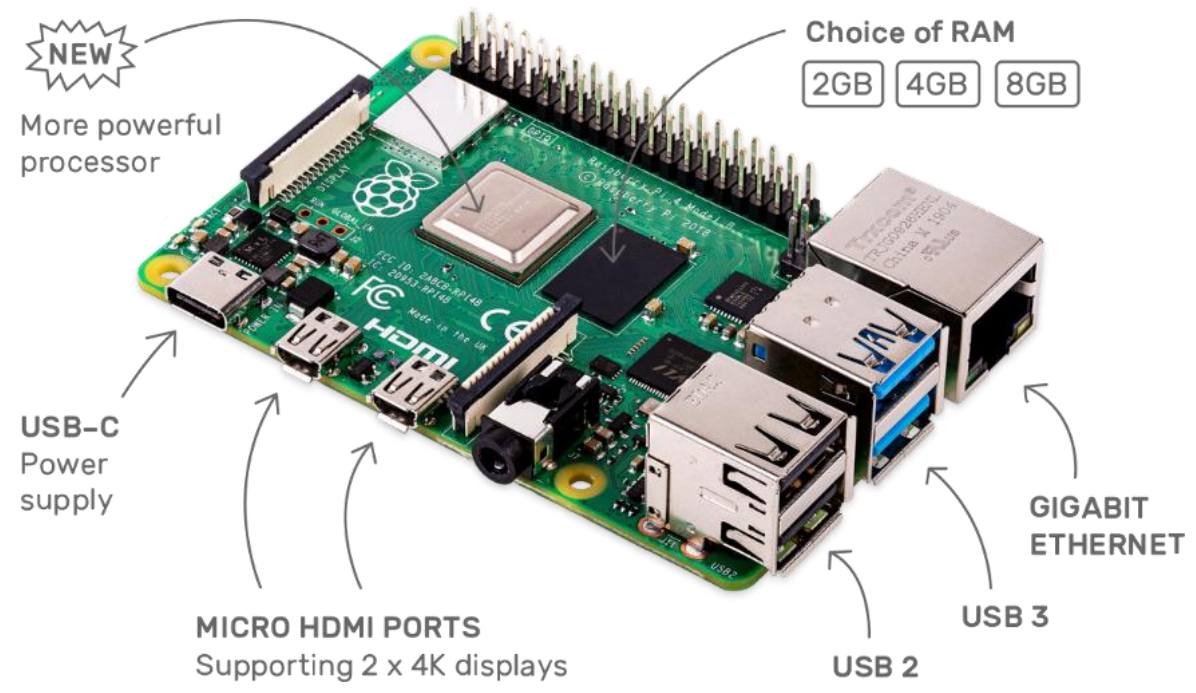

Fig. 2. Raspberry Pi 4 Model B [15]

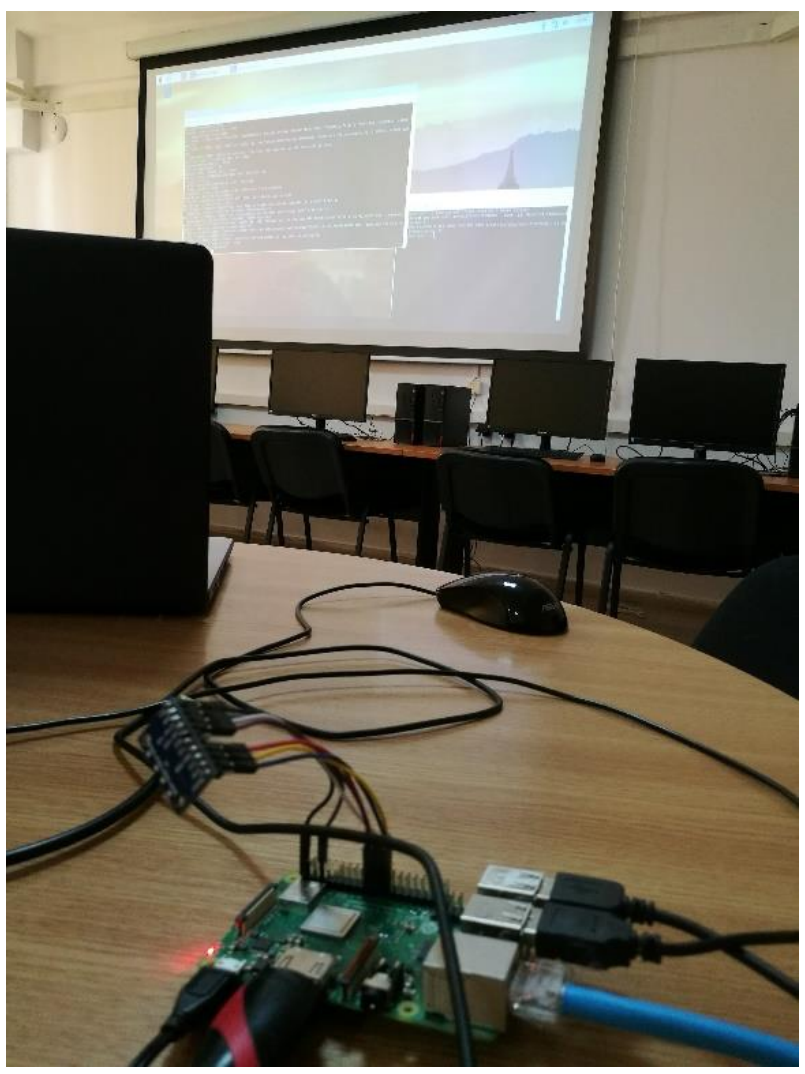

Fig. 3. Experimental system

The functionality of IoT in the educational system can be increased using concepts like LMS. An LMS is a concept (a software application) that emerged from e-Learning. An LMS can be used for documentation, tracking, reporting, administration, and automation of the educational process. This concept was originally created to identify learning gaps and training, using analytical data and reporting. Nowadays, LMSs contain intelligent algorithms. These components provide automated recommendations for courses. The input data for this process is the user's skill profile plus the metadata from course materials [16-18]. 
The system that we proposed uses Microsoft Team capabilities. This application can be used to develop professional course content. Using this application, academia, teachers, and instructors can add any type of content to learning materials (slideshows, images, tables, text, links, interactive tests, text formatting, etc.). In addition, course administrators can create multiple types of users (teachers, students, visitors, and editors). These futures (figure 4) add more functionality to the educational process by controlling which material a student can access and also by tracking studying progress.

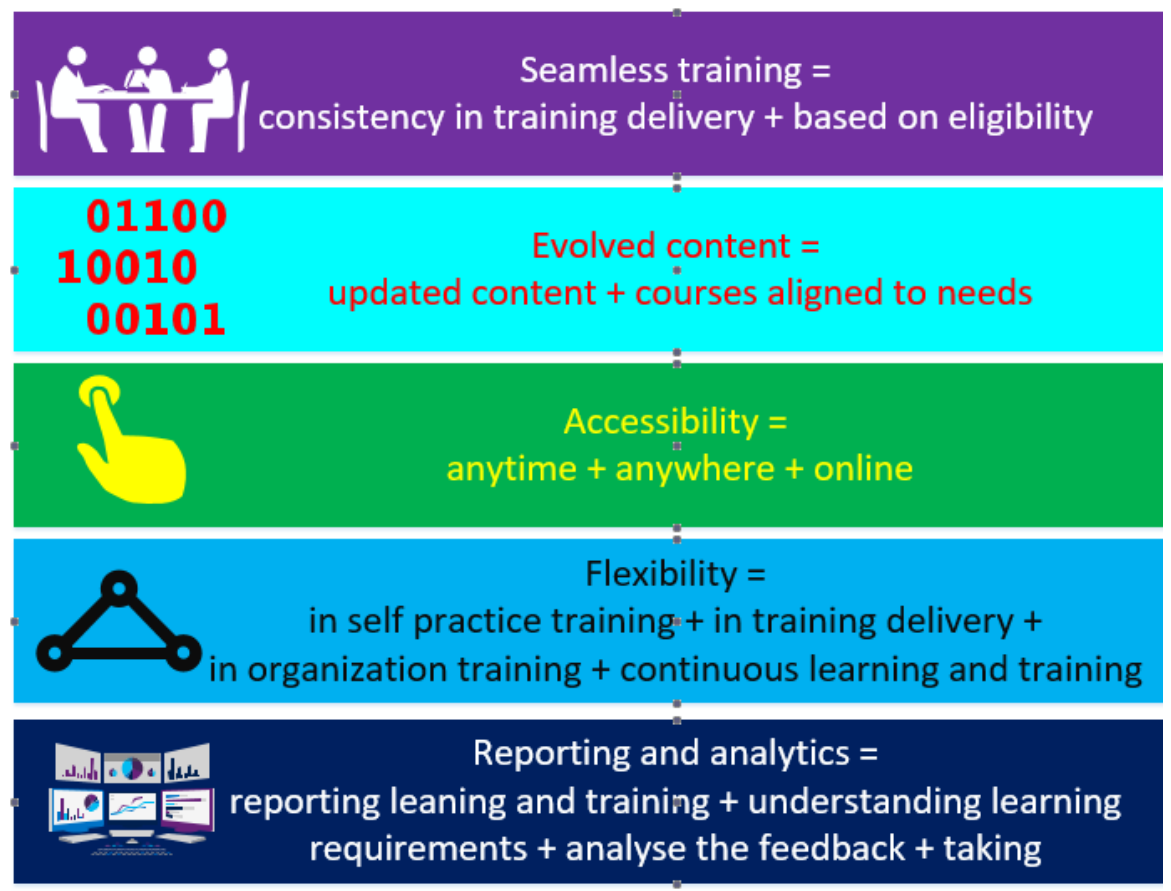

Fig. 4. LMS

\section{RESULTS}

The concept of IoT adds value to any organization. By connecting students, faculty, objects, and the environment, it is possible to develop improvements that can only be beneficial. The benefits of any organization are multiple. Academia and students can improve productivity. The IoT ecosystem permit monitoring and controlling of different educational processes. By optimizing different operations productivity and efficiency can be increased. Due to a large amount of information, predictive analysis of students' performance can be conducted. The available technologies allow recurring patterns to be analyzed. Thus, the IoT ecosystem contributes to predictive analysis. This information can be used even in educational process maintenance. Another benefit of the system is a rapid response to disasters or environmental changes. The data coming from the sensory layer can be monitored automatically in real time and remotely. This valuable data can be a strategic advantage. Autonomous systems are more reliable because minimize or eliminate human errors. IoT complementarity with AI (Artificial Intelligence) minimizes human errors due to trivial or repetitive tasks. The educational system is all about dialog. Thus IoT increases the ecosystem components dialog. This capability provides opportunities to increase interaction.

The IoT is a valuable asset in upgrading the educational system to make decisions and improve its performance.

An LMS can be an extraordinary tool to use not only in this current context. During the last months, we have identified not only advantages but also disadvantages (table 2). In a synthetized form, the advantages are: maintenance ability and adaptability, accessibility, reusability, durability, and interoperability. 
Table 2. LMS advantages and disadvantages.

\begin{tabular}{|l|l|}
\hline \multirow{4}{*}{ Advantages } & supports various form of content: text, video, audio, etc. \\
\cline { 2 - 2 } & the materials can be access anytime, from everywhere \\
\cline { 2 - 2 } & based on attendance and online quizzes, the evaluation process is easier and fair \\
\cline { 2 - 3 } & the course materials can be re-used \\
\hline \multirow{3}{*}{ Disadvantages } & teachers and students have to be willing to adapt to new \\
\cline { 2 - 2 } & courses can tend to be impersonal \\
\cline { 2 - 2 } & lack in the dialogue opportunities \\
\hline
\end{tabular}

\section{CONCLUSIONS}

Integrating both IoT and LMS will generate a revolution in the educational sector resulting in high effectiveness and efficient teaching methodology.

We propose a system that combines the Internet of Things concept along with a Learning Management system to generate a positive impact in cost saving, automation and control, information and communication and most importantly increasing productivity. This system represents a strategic advantage in any industry. But more in the educational process.

Face a promising future it is time to make the most of such technologies and transform the education system.

\section{Conflicts of Interest}

The authors declare no conflict of interest

\section{References}

1. Alrashed, S. Key performance indicators for Smart Campus and Microgrid. Sustainable Cities and Society 60, 102264 (2020).

2. Xu, X. et al. Research on Key Technologies of Smart Campus Teaching Platform Based on 5G Network. IEEE Access 7, 20664-20675 (2019).

3. Faritha Banu, J., Revathi R., Suganya M., Gladiss Merlin, M.R. IoT based Cloud Integrated Smart Classroom for smart and a sustainable Campus. Procedia Computer Science 172, 77-81 (2020).

4. Zhu, Z. M., Xu, F. Q. \& Gao, X. Research on School Intelligent Classroom Management System Based on Internet of Things. Procedia Computer Science 166, 144-149 (2020).

5. Gunasekera, K., Borrero, A. N., Vasuian, F. \& Bryceson, K. P. Experiences in building an IoT infrastructure for agriculture education. Procedia Computer Science 135, 155-162 (2018).

6. Ali, M. et al. IoTFLiP: IoT-based flipped learning platform for medical education. Digital Communications and Networks 3, 188-194 (2017).

7. Cavus, N. \& Zabadi, T. A Comparison of Open Source Learning Management Systems. Procedia - Social and Behavioral Sciences 143, 521-526 (2014).

8. Pecheanu, E., Stefanescu, D., Dumitriu, L. \& Segal, C. Methods to evaluate open source learning platforms. in 1152-1161 (2011). doi:10.1109/EDUCON.2011.5773292.

9. Jose, D. V. \& Vijyalakshmi, A. An Overview of Security in Internet of Things. Procedia Computer Science 143, 744-748 (2018).

10. Filipescu, A., Solea, R., Filipescu, A., Stamatescu, G. \& Ciubucciu, G. Trajectory-Tracking Sliding-Mode Control of the Autonomous Wheelchair Modeled as a Nonholonomic WMR. in 2018 IEEE 14th International Conference on Control and Automation (ICCA) 1168-1173 (2018).

11. Solea, R., Ciubucciu, G., Cernega, D., Filipescu, A. \& Voncila, I. Trajectory Tracking Nonlinear Control and Narrow Spaces Navigation of a WMR. in 2018 22nd International Conference on System Theory, Control and Computing (ICSTCC) 329-334 (2018). 
12. Solea, R., Margarit, A., Cernega, D. \& Serbencu, A. Head Movement Control of Powered Wheelchair. in 2019 23rd International Conference on System Theory, Control and Computing (ICSTCC) 632-637 (2019).

13. Sethi, P. \& Sarangi, S. R. Internet of Things: Architectures, Protocols, and Applications. Journal of Electrical and Computer Engineering 2017, 9324035 (2017).

14. Navani, D., Jain, S. \& Nehra, M. S. The Internet of Things (IoT): A Study of Architectural Elements. in 2017 13th International Conference on Signal-Image Technology Internet-Based Systems (SITIS) 473-478 (2017).

15. Raspberry $\mathrm{Pi}$ 4. Accessible at: https://www.raspberrypi.org/products/raspberry-pi-4-model-b/. (accessed on 20.08.2020).

16. Susnea, I., Pecheanu, E. \& Costache, S. CHALLENGES OF AN E-LEARNING PLATFORM FOR TEACHING CREATIVITY. in (2015).

17. Cocu, A., Pecheanu, E., \& Susnea, I. (2015). Stimulating creativity through collaboration in an innovation laboratory. Procedia-Social and Behavioral Sciences, 182, 173-178.

18. Pecheanu, E. Susnea, I., \& Tudorie, C. (2015). Initiatives towards an education for creativity. Procedia-Social and Behavioral Sciences, 180, 1520-1526. 